\title{
11 Studying Privileged Men's Career Narratives from an Intersectional Perspective: The Methodological Challenge of the Invisibility of Privilege
}

\begin{abstract}
Studying elites and, more particularly, privileged men is worthwhile because the favourable position of these individuals and groups in the social hierarchy allows them to make significant material and cultural impact on the world. Often, such an advantage is unearned and involves a sense of entitlement and lack of awareness of being in possession of it. It is therefore crucial to understand how this power operates and is maintained, by disrupting the invisibility of privilege. This chapter addresses methodological issues pertaining to the study of men, masculinities and privilege, drawing on privileged men's career narratives. I focus on a particular methodological problem I encountered when studying the career narratives of male managers from an intersectional perspective: the invisibility of privilege in these accounts. In sociological research, intersectional approaches typically assume identifying socially constructed categories of identity and difference in people's accounts of their experiences and studying relationships between these. However, the narratives of the male managers in question lacked references to social categories (gender, race, class etc.) in their self-descriptions. This chapter explores this problem and discusses some potential methodological solutions and ways forward. Finally, I suggest that some recent cultural changes and transforming gender relations are gradually marking privileged men and masculinities. Masculinity, then, is increasingly emerging from the status of an unmarked category.
\end{abstract}

\section{Introduction}

Intersectionality, originating from the work of Black feminist scholars (Crenshaw 1989: 1991), has become a key concept and theoretical approach in contemporary feminist and gender studies and has been adopted in some other areas of social 
sciences and humanities as well. ${ }^{1}$ Intersectional perspectives seek to understand how socially constructed categories, such as gender, race, class and age intersect and mutually shape each other in people's experience and how these intersections contribute to social inequality. As such, intersectionality helps to theorise power relations on various levels of the society in more nuanced and complex ways, compared to so-called unitary approaches focusing on one axis of power or social category at a time.

First emerging as a theoretical approach, intersectionality has also been discussed and developed as a methodology (see for example Bilge 2009; Choo and Ferree 2010; Hancock 2007; Lykke 2010; McCall 2005; Windsong 2016) and a specific research method (Lutz 2015). This scholarship has focused on various possibilities and complexities of conducting social science research from an intersectional perspective, both in quantitative and qualitative inquiry. While this work is useful in advancing our understanding of how to apply intersectionality as a methodological tool, some important gaps remain. Partly stemming from the original focus of intersectionality - to understand experiences of marginalised groups (specifically, the original focus was on Black working-class women in the US), intersectionality continues to be primarily used to study how various axes of power and social categories intersect to produce disadvantage. In other words, the focus has remained on marginalised groups and identities - those that are marked. Attention to privilege and privileged groups within intersectionality frameworks has thus far been scarce. This has been identified as a significant gap or missing element in some existing work (Lewis 2009, 209). This lack is also reflected in methodological discussions on intersectionality, which almost exclusively deal with questions of how to study intersections involving disadvantage. As a related and relevant observation to the discussion here, there is also a scarcity of (critical) methodological attention to men and masculinities (Pini and Pease 2013, 1).

I suggest that intersectionality could potentially be a useful approach to examine privilege and privileged groups who have mostly remained unmarked. Intersectionality could help understand how this privilege is produced and upheld. This argument stems from the premise that all identities and social locations are intersectional. It would be useful to reflect on and advance intersectionality as a more comprehensive theoretical and methodological framework able to explain not only experiences of marginalisation but also of privilege and social structures

1 This chapter is based on the analytical overview of my doctoral dissertation, entitled "Intersectional disadvantage and privilege in the Estonian labour market: an analysis of work narratives of Russian-speaking women and Estonian men” (2015). 
which sustain this privilege. Studying elites and more particularly, privileged men, is useful because the privileged position of these groups in the social hierarchy allows them to make significant material and cultural impact on the world. It is therefore crucial to understand how this power operates and is maintained (Donaldson and Poynting 2013), by disrupting the invisibility of intersectional privilege, or as Robinson $(2000,1)$ puts it, "[m]aking the normative visible as a category embodied in gendered and racialized terms can call into question the privileges of unmarkedness."

My aim in this chapter is to reflect on using an intersectional perspective to study privileged groups. The discussion in this chapter is based on my doctoral research on intersectional inequalities in the context of work and careers (Aavik 2015). As part of this research, I studied career narratives of white ethnic majority male managers in Estonia - a group I termed intersectionally privileged (Aavik 2015, 38). I aimed to understand how intersectional privilege figures in the narratives of these men and how it produces advantages for them in the context of work and careers. I was interested in how they "do intersectionality” (Lutz 2015, 41). Understanding power relations, inequalities and privilege from an intersectional perspective is important in the context of work and careers, as these are key sites where gender and other intersecting inequalities are reproduced as well as contested in the society.

In this chapter, I elaborate on one particular methodological issue that I faced when attempting to use intersectionality as a methodological framework in studying the narratives of Estonian male managers: invisibility of privilege in the narratives. I will suggest some potential solutions to this problem. This chapter seeks to contribute to a discussion on advancing intersectionality as a methodology in qualitative research focusing on studying privileged groups.

\section{Intersectionality}

The notion of intersectionality was originally coined by Kimberlé Crenshaw in 1989 and was intended to address the fact that the experiences and struggles of women of colour were not adequately attended to by either feminist or antiracist discourses. Crenshaw argued for the need to show how both gender and race (and other categories of difference) "interact to shape the multiple dimensions of Black women's experiences” (Davis 2008, 68), as they "are located at the intersection of racism and sexism and their experiences could be reduced to neither" (Kantola 2009,16). 
In contemporary gender and feminist studies, intersectional thinking has become almost taken for granted. Intersectionality has transformed how gender is being discussed (Shields 2008, 301). It is no longer acceptable to disregard differences within large social groups such as men and women and power imbalances linked to intersectional social positions that people occupy. Ways in which people identify themselves and are positioned in the social hierarchy in terms of these categories and their intersections, has implications for their ability to produce, negotiate and impose meanings in various social situations and settings, such as in the context of careers. Disregarding processes by which people become gendered, racialised, and classed etc. simultaneously and the implications this has for the production of individual selves as well as for the emergence and perpetuation of social hierarchies, will produce at best an incomplete or at worst, a distorted account of social reality. Instead, feminist intersectional approaches call for attention to ways in which gender and experiences of gender are shaped by other socially constructed categories.

Intersectionality, then, is conceptualised as "the interaction between gender, race, and other categories of difference in individual lives, social practices, institutional arrangements, and cultural ideologies and the outcomes of these interactions in terms of power" (Davis 2008, 68).

Intersectionality is distinct from additive approaches. Disadvantage and/or privilege that people experience, stemming from their position in the social hierarchy, is not cumulative, but interactional - "for example, racism is infected and changed by sexism for black women, and vice versa - the sexism they encounter is infected and changed by racism" (Bagilhole 2009, 50). In other words, intersectionality means mutually constitutive relations among social identities, that is, how "one category of identity, such as gender, takes its meaning as a category in relation to another", which means that "intersectional identities are defined in relation to one another" (Shields 2008, 302-303).

Several authors point to different levels of intersectional analysis that should be considered and conceptualised somewhat differently (see for example Crenshaw 1991; Cho, Crenshaw and McCall 2013). The two most distinct levels tend to be individual (i.e. examining intersections of categories in people's identities and experiences) and at the other end of the spectrum the structural/institutional level (examining ways in which inequalities are built into social structures and institutions). These levels are closely linked. Reflecting the ideas of several prominent intersectionality scholars, Lewis (2009, 207) notes: "thinking 'intersectionally' [. . .] involves thinking simultaneously at level of structures, dynamics and subjectivities; that it conjoins rhetorics of 'voice' and presence and rhetorics of discourse and institutional 
form; that it facilitates a form of feminist enquiry that aims to, and is capable of, capturing the complexity and multiplicity of axes of oppression".

While the focus of intersectionality has traditionally been on marginalised groups, intersections produce both oppression and opportunity (Shields 2008, 302). Thus, intersectionality could be useful to explore how some (privileged) groups reinforce and retain their position of power and privilege in the society. Choo and Ferree $(2010,133)$ argue that "intersectional analysis should offer a method applying to all social phenomena, not just the inclusion of a specifically subordinated group". They therefore suggest that inequality should not be reduced to diversity, as methodologically, inclusion of marginalised groups "fetishizes study of "difference" without necessarily giving sufficient attention to its relation to unmarked categories, especially to how the more powerful are defined as normative standards" (Choo and Ferree 2010,133).

Finally, it should be mentioned, without being able to go into further detail on this, that intersectionality has also been recognised as a contested theoretical framework, for various reasons. For example, queer and sexuality studies scholars argue that in studying how categories relate to each other, binaries are often reproduced (Taylor, Hines and Casey 2010, 2).

\section{Understanding Privilege through Intersectionality}

A key impetus behind my research on the careers of Estonian male managers was that the role of privileged groups, such as ethnically/racially and otherwise unmarked men working in management positions in sustaining and reproducing social inequalities, is of great significance (Collinson and Hearn 1994; Aavik 2015). In the context of work and careers, members of groups located at privileged intersections of gender, ethnicity, class and other categories are better able to correspond to the image of the ideal worker (Acker 1990) due to the invisibility and normalisation of this privilege. This is likely to help them advance in their careers better compared to other, less privileged groups.

To better understand this privilege conceptually, I turned to existing work in gender studies and beyond aiming to understand and expose privilege (see for example Pease 2010, 2014; Bailey 1998). I found particularly useful insights from critical race and whiteness studies, which have focused on exposing and challenging white privilege and normativity. Scholars of critical studies of whiteness have explored how whiteness is constructed as an invisible norm. The status of an intersectionally "unmarked" group (in terms of several categories simultaneously) is 
conceptually similar to the phenomenon that critical whiteness studies scholars have observed: the way in which whiteness appears as a "racially neutral site" (Twine 1997, 228), or a "natural state of being” (Frankenberg 1997, 15-16). Critical whiteness studies aim to expose whiteness as a privileged category, displacing it from an unmarked status (Frankenberg 1993, 6; Twine and Warren 2000, 20). In addition to critical whiteness studies, inspiration could be drawn from other fields of academic inquiry which aim to expose normativity and privilege that remain mostly invisible. Fotopoulu (2012) and Pini and Pease (2013) suggest an engagement with queer theory, due to its "inherent concern with de-naturalizing normative categories” (Pini and Pease 2013, 12). Stemming from a similar logic, there have been suggestions to use insights from critical heterosexualities studies and disabilities studies (Bridges 2019).

Advantages experienced by the subjects of my study in the context of work and careers stemmed simultaneously from their privileged position on the axes of gender, race and ethnicity as well as their managerial status. ${ }^{2}$ These categories intersect and shape each other and help to secure the continued hegemony of people positioned as such in the labour market as well as in the social hierarchy more broadly. I proposed the term intersectional privilege (Aavik 2015, 38) to describe the situation where various social categories contribute to privilege at the same time. I understand as intersectional privilege the opportunities and advantages that are systematically available to individuals or groups in particular social contexts and situations due to their privileged position on the axes of gender, age, ethnicity, race and other relevant social categories simultaneously. A particular feature of intersectional privilege is that the mechanisms, by which it is perpetuated, tend to remain invisible and uncontested by members of intersectionally privileged groups themselves, and often also by others. This is possible because members of intersectionally privileged groups remain unmarked. Such structural advantage is unearned and involves a sense of entitlement and lack of awareness of being in possession of it (Bailey 1998, 108, 113; Pease 2014, 21). The particular positioning of the interviewed Estonian male managers in relation to other groups in the Estonian labour market leaves them unmarked in most situations in terms of multiple categories simultaneously, which constitutes a key source of their intersectional privilege.

In this instance, it may look like this is a case of cumulation of privileges an additive approach that intersectionality rejects. These privileges however do

2 Certainly, other categories played a role (the list is potentially endless), but were not in the explicit focus of my study. In the context of my study, I identified gender and ethnicity as the most relevant ones. The inclusion of more categories would have complicated the analysis significantly. 
not simply "pile up", but there is a complex interplay between them. The particular categories at play reinforce and give meaning to each other - in the case of my research participants, their Estonian ethnicity was shaped by their gender as men and vice versa. These categories interact to render each other invisible. For the Estonian male managers in my study, performing masculinity in the context of work and career is facilitated by their association with the dominant ethnic group and their high position in the work hierarchy. Hence, it becomes important to examine in detail, how these categories interact and mutually support each other to produce privilege.

This type of scholarship can be located in what Brekhus (1998) has termed as the sociology of the unmarked. He calls for sociology to pay more attention to the "'politically unnoticed' and taken for granted elements of social reality" (Brekhus 1998, 34). The subject matter of this kind of research and intersectional privilege qualify as unmarked elements of social reality. Yet, remaining unmarked has become increasingly difficult, even for the traditionally unmarked groups, such as white middle-class men. I will come back to this point in my concluding remarks.

\section{Using Intersectionality to Study Privileged Men's Career Narratives: The Problem of the Invisibility of Privilege}

Intersectionality, while a valuable theoretical approach, has introduced a variety of methodological challenges, as a number of scholars have admitted (McCall 2005, 1772; Bowleg 2008, 312; Shields 2008, 301, 305; Ludvig 2006, 246). In this section, I discuss, based on my own research, some particular issues pertaining to applying intersectionality to study privileged groups, specifically, intersectionally privileged men's career narratives. More particularly, I examine the methodological problem of invisibility of privilege.

The research material that informs this discussion originates from interviews with ethnic Estonian men working as middle and top managers in the private and public sectors. I conducted 15 interviews in 2012-2013, as part of my doctoral dissertation. Research participants were aged between 27 and 74 (average age was 42). Most of them were based in the capital Tallinn, with two located in another major town of Estonia. The central theme of the interviews focused on the work and careers of the managers. I was interested in how they 
make sense of the progression of their careers, including, importantly their ascent to managerial positions.

A number of feminist and critical men and masculinities studies scholars have highlighted methodological issues pertaining to differently positioned research participants in feminist research (see for example Pini and Pease 2013, 6; Hearn 2013, 27; Kirsch 1999). Certainly, the way I as a researcher was positioned in relation to my research participants, shaped my interaction with them, including their self-presentations. I encountered some issues having to do with "studying up" (Harding and Norberg 2005; Donaldson and Poynting 2013) ${ }^{3}$ related to power imbalance of the interaction, with them having more power resources at their disposal.

As a general principle, feminist researchers seek to reduce power hierarchies between the researcher and research participants in the research process and empower the latter. However, these aims do not always apply in the case of studying elites, which is an instance of "studying up" (Harding and Norberg 2005; Donaldson and Poynting 2013). Indeed, the concern is reversed here and the question becomes how not to consolidate the privileged position enjoyed be these groups by placing them at the centre of research and making their perspectives heard. Instead, studying up should involve identifying "practices of power and how they shape daily social relations" (Harding and Norberg 2005, 2011).

While my data collection and analysis followed key tenets of narrative research (Lawler 2002; Gubrium and Holstein 2008, 2009), the insights below apply to qualitative methods in social sciences more generally.

\section{Defining the Problem}

Intersectionality scholars maintain that "the relationship between categories is an open empirical question" (Hancock 2007, 64), and as such, for the researcher to identify. The principal task of intersectionality researchers is to make "the intersections between ethnicity, sex/gender, sexual orientation (to name just a few) and the social inequality related to these identities, explicit" (Bowleg 2008, 322). It is this central task that has produced a number of methodological challenges for researchers attempting to apply intersectionality as a

3 For a discussion of methodological issues in interviewing powerful men, such as senior managers and corporate elites, see Hearn 2013, 28-29. 
methodological tool. This includes issues having to do with identifying social categories in the personal narratives.

To study how socially constructed categories such as race/ethnicity and gender are manifested in the narratives and relate to each other, as required by the intersectional approach (Shields 2008, 307), I turned to a specific method, known as "asking the other question" (Matsuda 1991, 1189). As the first step, this involves identifying relevant social categories in the account and analysing how each of them shapes the narrative separately (Bilge 2009, 5-7). As the second step, it is then considered how these categories interact with each other (Choo and Ferree 2010, 135; Bilge 2009, 5-7).

It was when attempting to conduct this crucial step of the analysis where I ran into trouble: it was nearly impossible to identify explicit references to social categories, such as gender or ethnicity in the career narratives of the Estonian male managers - they were simply absent. The interviewees tended to talk about themselves (and often, about others) typically without any explicit references to gender and ethnicity (the primary categories I was interested in), ${ }^{4}$ despite the fact that they were interviewed as Estonian male managers. Because of such silences and absences regarding these categories and the interviewees' self-presentation as just generic people or managers in their career narratives, it is difficult to illustrate this problem with short and concise interview extracts - rather, this becomes evident when examining their entire narratives. However, talking about the self in generic terms became more evident in their occasional references to differently positioned others (e.g. colleagues) as gendered or ethnicised or when I explicitly brought in gender and ethnicity. I will present a few examples of this later on.

This assumption behind the idea of intersectionality - the presence and visibility of social categories in people's narratives of their lives - and my struggle to find these categories in the narratives of this privileged group led me at first to treat these narratives as somehow deficient, in terms of their content and the ways they were produced. I initially located the problem in specific gender performances of the group I was studying and the kinds of narratives this produced. I was confronted with "configurations of masculinity that prize stoicism and inexpressiveness” (Bridges 2013, 54). This often resulted in rather truncated narratives and particularly in some interviews took the form of exchanges of questions and short answers, as several interviewees preferred short and

4 It is worth noting here that a particular feature of the Estonian language contributed to the absence of the category of gender from their talk: there is no grammatical gender in Estonian, the same pronoun is used to signify "he" and "she". Hence, the gender of other people (colleagues, superiors etc.) they talked about in their narratives could not be discerned, unless they used first names to refer to these people. 
concrete ways of expression, rather than presenting their experiences in narrative form. Among other issues, this brevity may have had to do with the fact that most interviewees presented almost exclusively only their work-related selves, and refrained from dwelling on how other parts of their lives might have shaped their careers and work-related identities.

While these factors certainly played a role, I would argue that this was not the main problem in this case. Instead, it may be useful to ask questions about the specificities of intersectionality as an analytical approach.

The expectation for the presence of categories in the interview material, which is taken as a prerequisite for an intersectional analysis, seems to imply that people always make references to social categories in speaking about themselves and their experiences in some form or another: for example, in the case of my interviewees, talking about themselves as men or Estonians and as Estonian men. Based on my research with intersectionally privileged men, I challenge this assumption and claim that such a self-presentation where the speaker marks their identity more explicitly is rather a feature of narratives produced by marginalised individuals and groups.

Stemming from the assumption that if categories matter, they will be visible in narratives, Jimerson and Oware (2006) have studied how Black male basketball players invoked the categories of gender and race in their talk, and identified specific ways of doing Black masculinity. However, an implicit feature in identifying these categories and their relationships for researchers in this context seems to have been the fact that while the category "man" remains unmarked in most situations, the category "Black" does not. In this case, the racialisation of these men made them and their masculinity marked. This helped to make visible the otherwise unmarked category of masculinity. Thereby, these men's doing of intersectionality was visible and particular, as manifested in their talk.

In the case of the white (non-racialised) ethnic majority Estonian men in my research however, this mechanism did not apply, as they remain unmarked in most situations in terms of important categories, such as gender, ethnicity, age, ablebodiedness, and sexual orientation, to name a few, certainly in the context of managerial work and careers in the Estonian labour market. I argue that this constitutes a source of their intersectional privilege. Hence, neither of these categories functioned to mark others or make them visible. And this is reflected in their career narratives.

Based on these insights, it could then be concluded that the assumption that categories should be visible in narratives, in some form or another, if they are relevant, applies primarily to those identity positions, where at least one category is present in its marked dimension, for instance, "Black man", as in the example above. It is in the accounts of individuals positioned as such, that the categories are likely to be more immediately visible or more explicitly articulated, or at least 
more recognisable to researchers. The invisibility of categories in the case of intersectionally privileged groups who are in possession of considerable power resources - such as the Estonian male managers I interviewed - means that we may not be directly able to see this in the interview material. In other words, narratives originating from such individuals and groups may not provide enough evidence of how their social power and privilege functions discursively. This problem is eloquently articulated by Sally Robinson in her work on white masculinity in the contemporary USA: "Masculinity and whiteness retain their power as signifiers and as social practices because they are opaque to analysis, the argument goes; one cannot question, let alone dismantle, what remains hidden from view" (Robinson 2000, 1).

What do these insights then tell us about intersectionality and its usefulness as a methodological approach to understand all identities and social positions, particularly the privileged? Can it be concluded from this that intersectionality as a tool is more suitable for analysing narratives exhibiting certain features than others? It does seem indeed, that methodologically, intersectional research so far is better equipped to explore marked identity positions - that is, to study those who differ from the (invisible) norm. This stems from the particularities of the origins of intersectionality - as a conceptual tool to understand marginalised identities and groups.

\section{Potential Solutions}

Below I discuss some ways in which the problem may be tackled, based on my analysis of the narratives of Estonian male managers. Some of these solutions I resorted to myself while others are simply ideas to be developed further and tested on empirical data.

\section{Considering (Narrative) Context}

One of the most obvious solutions involves following the key tenets of qualitative research - understanding qualitative interviews as social products that are always situated. This is a central principle in narrative research as well. Narrative scholars call for interpreting narratives in context or in environments in which they are produced (Gubrium and Holstein 2008, 2009; Phoenix 2008). This environment can refer to the more immediate context, such as the interview setting and the way in which the interviewer is positioned in relation to the interviewees. Importantly, it also refers to the larger social, political and cultural settings. In 
other words, this means viewing personal narratives "within a larger sociohistorical context of structural inequality that may not be explicit or directly observable in the data" (Bowleg 2008, 320).

Locating the narratives in a larger social and historical context has also been suggested by some intersectionality scholars to help understand why research participants might articulate certain categories more explicitly while remaining more implicit regarding others, as Yuval-Davis $(2006,203)$ notes: "in specific historical situations and in relation to specific people there are some social divisions that are more important than others in constructing specific positionings". Lewis, echoing discussions held at a prominent intersectionality conference held in 2009, highlights "the need to always pay consistent attention to the historical and social contexts in which the categories being invoked (analytically and/or experientially) are produced, made meaningful and deployed. The key point here is the need to address the political and this requires paying attention to which set of categories are brought into alliance and with what political agenda in mind" (Lewis 2009, 205). The implication is that context invites people to think about their experiences in certain ways, favouring invoking certain categories over others.

I followed this advice throughout my analysis to understand and explain the absence of categories of gender and ethnicity in the narratives of the Estonian male managers. This silence in these narratives was especially striking in contrast to interview material I collected in the first part of my doctoral thesis: narratives of Russian-speaking women in Estonia who were unemployed or performed manual work. Representatives of this latter group typically spoke of themselves as Russian-speakers or ethnic Russians, strongly emphasising ethnicity as an important dimension of their identity. They emphasised gender to a lesser extent; however, the presence of gender could be quite easily identified in segments of their narratives, for instance, where they invoked their identities as Russian mothers.

Certainly, understanding the social and political context of Estonia is helpful in interpreting these narratives and explaining why categories, particularly ethnicity, were salient in the narratives of the Russian-speaking women. For one, ethnicity is a very politicised category in Estonia. However, it is only "nonEstonians" who stand out as marked in terms of ethnicity in Estonia. Estonians remain in the status of an unmarked group. When making sense of their careers in the Estonian labour market, the interviewed Estonian male managers simply did not frame their experiences through the categories of ethnicity and gender. Also, the way in which the interviewees were positioned in relation to me as an interviewer was significant. In interviews with the Estonian male managers, ethnicity could have been silenced or treated as an irrelevant category because as Estonians, both the interviewees and myself we were positioned at the 
privileged and unmarked end of the category of ethnicity. This was despite the fact that ethnicity (along with language) is a politicised category in Estonia (for more on this, see Aavik 2015, 24). The fact that ethnicity did not come up as a category in the work and career narratives, illustrates how people and groups at the privileged end of this category are still able to remain unmarked in terms of this social division, at least in the context of work and careers.

I suggest that some other contextual elements also played a role in shaping narratives of career paths in such a way that there were only minimal references to gender and ethnicity. For example, the neoliberal ideology prevalent in Estonia encourages conceptualising people as individuals not as members of a collective or group, while obscuring structural inequalities which create advantages and/or disadvantages for individuals positioned in certain ways. Relating to this, references to the categories may have also been absent because in the realm of professional work, focus is typically on the individual or professional worker and his/her achievements, not on gendered, racialised or ethnicised subjects (Chase 1995).

However, understanding the experiences of intersectionally privileged groups as shaped by the narrative environment in which they emerged, while taking us forward, is in my view only a limited solution to the problem of detecting how intersectional privilege manifests itself and what it means in personal narratives. For one, the suggestion to analyse narratives (of intersectionally privileged groups) in context in this case does not seem to be a particularly special solution, since all qualitative empirical data only makes sense in a context, and should always be interpreted in such a way. It is thus only a partial solution and not specific enough to deal with the specificities of the narratives of intersectionally privileged groups. Another potential problem of using only this approach involves the risk that the researcher departs too much from the actual narratives themselves and imposes external constructs on the data, in attempting to explain intersectional privilege and its sources. Crucially, this kind of analysis might end up being too speculative, where absences are accounted for by invoking only some contextual factors and not others. The process by which the researcher makes these decisions often remains invisible.

The task of making "explicit the often implicit experiences of intersectionality, even when participants do not express the connections" (Bowleg 2008, 322), also invokes other problems related to interpretation of qualitative data. For example, it disregards the ways in which participants make sense of their own lives and experiences. 


\section{Absence of Social Categories in Narratives as an Indication of Intersectional Privilege}

One way to attempt to tackle the problem is to think that these silences or absences - the fact there is simply nothing to grasp in terms of categories in the narratives - are significant findings themselves. Even further, this could be thought of as the proof we are looking for that points to the privileged position of the research subjects - the fact that they tend to construct themselves as generic human beings and that their narratives do not contain experiences of discrimination or othering based on gender, ethnicity or other categories is evidence of their privilege. This is because other, more disadvantaged groups do not have the luxury of thinking of and presenting themselves as generic human beings. On the other hand, the narratives of the privileged may include references to other people and groups as gendered, racialised, ethnicised etc., which can tell us something about their own privileged position.

Here it is insightful to turn again to the field of critical whiteness studies, which I referred to earlier in this chapter, noting how scholars studying whiteness deal with an issue that is conceptually similar to intersectional privilege. I have found this body of work to be more insightful than much scholarship in critical studies of men and masculinities in examining and challenging invisible norms (whiteness, in this case). In critical whiteness studies, it is the unmarked nature, normative status and ordinariness of whiteness which are seen as defining features of white privilege. While this is an important insight, it poses methodological problems, as scholars of whiteness have experienced. They have noted that methodologically, to expose and challenge whiteness, as an unmarked category but at the same time a significant source of privilege for subjects associated with this category, can be extremely challenging. How to capture something that invisible in social interaction, including in interview settings?

While the absence of categories in narratives of the privileged certainly does point to their privileged position, it is a rather general statement and does not say anything specific about this privilege. Thus, to simply conclude that this is what counts as evidence for an intersectionally privileged social position or identity does not seem to be sufficient. The question still remains if there is anything else that can be detected in these accounts that helps to point to intersectional privilege and how it works. 


\section{Interview Guide and Interview Process}

Some scholarship discussing intersectionality as a methodology discusses points to the potential solutions lying in research design. More specifically, we could think whether there are ways to design the interview guide and carry out interviews in a way that helps us to detect what we are looking for.

One of the main methodological challenges in compiling the interview guide and preparing questions to be asked from research participants is "how to ask questions about experiences that are intersecting, interdependent and mutually constitutive, without resorting, even inadvertently, to an additive approach?” (Bowleg 2008, 314).

This issue has been approached differently by intersectionality scholars. For example, Windsong (2016), interested in meanings that people assign to neighbourhood through race and gender, first asked questions about these categories separately, followed by questions about how research participants see these as intersecting. She however notes that the intersectionality questions did not work well and caused confusion among her interviewees (Windsong 2016, 9). Windsong (2016) also asked her research participants to bring examples of situations where gender or race was more important for them. Bowleg $(2008,314)$, however takes an opposite approach, suggesting that research participants should not be asked to isolate or rank dimensions of their identities. Instead, she argues that "a truly intersectional question would simply ask the respondent to tell about her experience without separating each identity” (Bowleg 2008, 315). She suggests, based on her study of the experiences of Black lesbian women from an intersectional perspective, two key points to which researchers should attend when constructing questions about intersectionality. "First, questions about intersectionality should focus on meaningful constructs such as stress, prejudice, discrimination rather than relying on demographic questions alone", as "concepts such as race and class are socially constructed, and as such, explain virtually nothing in and of themselves" and second, "questions should be intersectional in design" - they should stress the interdependence and mutuality of identities rather than imply that "identities are independent, separate and able to be ranked” (Bowleg 2008, 316).

Bowleg's approach links best with my research design and specifically, with the narrative method I used. My interview questions revolved around central themes of work and careers. I asked my research participants to narrate their work experiences and career paths in detail, without drawing attention to social categories myself, at least not initially. However, if they spontaneously made such references in their narratives, I pursued these further. After they had finished telling the stories of their work and careers, in the later stages of 
the interview, I asked about their views on gender (and to a lesser degree, ethnic inequalities) in the Estonian labour market. Talking about gender however, meant not explicitly talking about themselves as gendered beings but focusing on women's "difference” from the male norm and framing gender inequality as an issue that concerns women. In the following excerpt, a research participant talks about his female colleague and women in managerial positions more generally:

It is impressive how she [an older female manager in the same organisation] is able to handle [her subordinates] [. . .]. She is a balancing and motherly figure in this predominantly male company.

The same interviewee, when presenting his own career and work as a manager, does not however refer to his gender when describing how he relates to his colleagues and copes with work. He and others constructed themselves simply as people or managers, not as Estonian male managers, silencing their gender, ethnicity and other categories in the context of careers.

In the following extract, Russian-speaking women were not only constructed as different, but also inferior, in relation to the implicitly present Estonian male norm:

Russian women for example are like . . . very dutiful and fast workers. [. . .] But some people will never become independent engineers, they need someone to be there to tell them how to do things. Well, people are different, but mostly those people who never become independent, are women however.

Unlike in this excerpt, in their descriptions of themselves, the interviewees do not stand out as men or Estonians.

The question of whether researchers should address intersectionality in interviews directly or refrain from doing so (Windsong 2016, 9) is a difficult one. It relates to the methodological question of "how should researchers design interview questions that reflect both the research interests and also allow participants to share their own experiences in the most valid manner?" (Windsong 2016, 9).

Explicitly addressing intersectionality in interviews may be tricky, as it is first and foremost an academic concept and does not necessarily resonate with people's lived experience (Windsong 2016, 9). The social categories that people are grouped into and identify with "are interdependent and mutually constitutive (i.e. intersectional [...]), rather than independent and uni-dimensional" (Bowleg 2008, 312). This means that it may be difficult to distinguish how these categories figure separately in people's lived experiences and narratives of their lives. 
These considerations shaped my choice not to make my interviews about gender, ethnicity and their intersections, but rather letting research participants present and frame their experiences in ways that seemed most meaningful to them. Keeping the themes of work and careers central to the interviews, rather than directly focusing on gender and ethnicity, was important also for other reasons, for example having to do with recruiting potential research participants. Approaching Estonian male managers with a request to interview them about what being positioned as an Estonian man means to them, would likely have confused them and may not have been considered a legitimate request in the Estonian context. Some scholars have documented challenges of interviewing white people about their whiteness. Frankenberg $(1993,23)$, for example, encountered bewilderment from the part of research participants when asked about their whiteness - this was a "'taboo' topic that generated areas of memory lapse, silence, shame, and evasion”. Similar insights apply to the context of my study - being positioned as an Estonian man does not appear for most people to be significant or special (enough) identity to study in the Estonian context, in contrast to, for example, asking Russian-speaking women in Estonia to talk about their experiences related to ethnicity and gender, which can be seen as a more legitimate inquiry, as this group does not appear as "ordinary", but stands out as "different".

These insights suggest that explicitly asking about gender, ethnicity and other dimensions of identity and their intersections, particularly in the case of privileged groups or refraining from asking such questions in interviews, both have certain shortcomings and may not help to arrive at narratives in which the privilege and power of research participants is clearly discernible.

\section{Turning to other Research Methodologies and Methods}

In addition to asking questions about the particularities of intersectionality and its application to studying intersectionally privileged groups, it may also be that the specifics of the narrative approach may not encourage the emergence of social categories in the narratives of the privileged. As already suggested in the previous section, narrative approaches favour minimal (prior) structuring of interviews by the researcher, open interview questions and relatively little explicit guidance from the interviewer, other than introducing topics to talk about and encouraging research participants to describe their experiences at length (Jovchelovitch and Bauer 2000). Research participants' own meanings and ways of framing are prioritised, rather than structuring interviews according to researchers' concepts and theoretical interests. 
Also, narrative analysis might be limiting because of what the method encourages us to notice and study. Narrative analysis is particularly suitable for examining how people present their lives and experiences in storied formats, and how they talk about their past and present selves. However, members of privileged groups may have never seen themselves as marked in any way throughout their lives, which means that more detailed attention to narratives in this case may not be helpful. Thus, an intersectional narrative approach might not yield findings that are nuanced enough to detect more subtle features of talk that might be of relevance to tackle the problem discussed here. There might be some special features present in the accounts of the unmarked which an intersectional narrative approach is unable to capture well.

It may then be that other qualitative methods could be more fruitful in this case which pay more detailed attention to language and smaller units of talk, such as discourse analysis or conversation analysis. To end this section, I will briefly consider the latter.

Emerging from the microsociological tradition, inspired by the work of Erving Goffman and Harold Garfinkel, conversation analysis (see for example Heritage 2008; Heritage and Clayman 2011; Liddicoat 2007) is a method that seeks to capture how people construct meaning in everyday conversation, in micro-interactions. Typically, naturally occurring data is used to study this (as opposed to material obtained through an artificially created interview situation).

Conversation analysis pays close attention to segments of text by understanding talk as action, focusing on immediate consequences of utterances and on what participants accomplish in an interaction. By this more detailed focus, this approach could help better understand the discursive means through which speakers conceal how power operates in interactions and ways in which normality is accomplished. This approach might provide opportunities for studying ways in which ordinariness and normality that are key features of intersectional privilege are in fact accomplished and understand the work that goes into it.

\section{Discussion and Conclusions}

This chapter has focused on methodological questions pertaining to the study of intersectional privilege (Aavik 2015), drawing on my previous research on the work experiences and career paths of Estonian men working in managerial positions. Specifically, I have discussed how an intersectional approach could be used in qualitative research to make sense of the lives and experiences of 
the privileged - a thus far relatively unexamined angle, given that intersectionality's theoretical and methodological origins and empirical focus have overwhelmingly been on marginalised groups.

The chapter began with an introduction of the notion of intersectionality and the concept of intersectional privilege. I then attempted to outline the methodological problem of invisibility of privilege: privileged groups - such as white middle-class ethnic majority men - do not tend to construct their lives and experiences through categories of gender, ethnicity, race, class etc. Their narratives exhibit silences and absences regarding these categories. This stems from the way these groups are positioned in the social hierarchy: the privileged ends of the categories of gender, race and class they are associated with - as male, white, ethnic majority and middle-class - are typically seen as generic and normative, unmarked and hence invisible. Methodologically, it is rather challenging to identify something that is unmarked, as a number of critical whiteness studies scholars have noted about whiteness, which has remained an elusive category to understand and also to bring up in interview settings with people identified as white. Yet, exposing privilege and ways in which it works is a crucial task, as "privilege works best when it goes unrecognized" (Bridges and Pascoe 2014, 256).

How should we then examine accounts lacking explicit references to social categories, which seems to be a characteristic feature of narratives produced by unmarked privileged groups? I discussed four different angles which may be helpful in tackling the issue, outlining the potential and limitations of each of these: 1) understanding narratives as situated social products and relying on a broader social, political and cultural context for providing explanatory power 2) considering the absence of categories as a significant finding in itself and deciding that this is the defining feature of intersectional privilege 3) developing a research design, including interview questions that would better help to identify privilege in personal narratives, including asking about intersectionality and privilege directly 4) turning to other methodologies and research methods, notably those that explicitly focus on language and smaller segments of talk to identify how power and privilege work in people's accounts of their lives.

Each of these approaches offers promising opportunities, yet, also entails certain problems. Despite these difficulties, we should not abandon intersectionality as a methodology and a tool to study the lives of the privileged and ways in which privilege manifests itself in their narratives, but continue methodological discussions on how to advance intersectionality. Intersectionality could be a useful approach to study all identities and social positions, including the privileged and unmarked ones, given that all identities and social positions are intersectional, even if some do not appear as such. We need to think 
of better methods by which the unmarked elements of social life, including unmarked social categories, could be seen in people's representations of their lives. At the same time, these methodological developments must consider changing social conditions which shape individual performances of gender, intersecting with other categories.

There are currently some interesting and significant changes taking place in Western societies regarding the construction and presentation of masculinities, which invite us to rethink how we study men and masculinities. As a substantial development, masculinity is increasingly becoming more visible (Bridges and Pascoe 2014; Bridges 2019). This is aptly illustrated by the idea of hybrid masculinity, which involves privileged Western "men's selective incorporation of performances and identity elements associated with marginalized and subordinated masculinities and femininities" (Bridges and Pascoe 2014, 246). Masculinity, then, is gradually emerging from its status of an unmarked category (see for example, Robinson 2000). This is also true of other forms of privilege, such as ethnicity, class etc. and their intersections. For example, whiteness may gradually become a (more) marked category and displaced from its normative status. For example, in contemporary culture, we are witnessing the gradual marking of white middle-class men as a distinct identity and social position, associated with considerable power resources. This has occurred largely as a result of the mainstreaming of some feminist ideas and in the context of the recent \#MeToo movement which have critically engaged with such intersectionally privileged men and masculinities. This means that it is becoming more and more difficult for people positioned as white middle-class men to remain invisible in terms of gender, race and class and claim the status of a generic human being.

These developments are likely to change the ways in which privileged groups discursively produce their selves and identities. However, as Bridges and Pascoe $(2014,256)$ argue, "when privilege becomes visible [. . .] it does not necessarily cease to exist". Instead, inequalities have the tendency to adapt and endure (Bridges 2019). While hybrid masculinity involves borrowing elements from marginalised groups, men who engage in this process, are able to retain their privilege (Bridges and Pascoe 2014, 246).

In the context of the focus of this chapter, this suggests that even if intersectionally privileged groups talk about themselves through gender, ethnicity, race, class and other relevant categories and thereby make these categories explicitly visible in their narratives - it does not mean that their privilege and power are necessarily challenged. If my interviewees explicitly spoke about themselves (not only in the interview setting but in everyday life as well) as gendered and ethnicised beings, and framed their career paths through these 
categories, would this somehow challenge their power and privilege in the labour market and society more broadly? It might be that such self-presentations may make it harder for them to remain intersectionally invisible in some contexts, which their work-related success partly depends on. Yet, there would likely be other discursive and material practices through which they sustain their privilege.

\section{References}

Aavik, Kadri. 2015. Intersectional Disadvantage and Privilege in the Estonian Labour Market: An Analysis of Work Narratives of Russian-Speaking Women and Estonian Men. PhD diss., Tallinn: Tallinn University Press.

Acker, Joan. 1990. “Hierarchies, jobs, bodies: A theory of gendered organizations.” Gender \& Society 4(2): 139-158.

Bagilhole, Barbara. 2009. “For Diversity Against Discrimination: From Gender Mainstreaming, through Multiple Discrimination, to Intersectionality." In Teaching Intersectionality: Putting Gender at the Centre, edited Franken, Martha, Alison E. Woodward, Anna Cabo Cardona, and Barbara Bagilhole, 45-52. ATHENA3 Advanced Thematic Network in Women's Studies in Europe. University of Utrecht and Centre for Gender Studies, Stockholm University.

Bailey, Alison. 1998. “Privilege: Expanding on Marilyn Frye’s Oppression.” Journal of Social Philosophy 29(3): 104-119.

Bilge, Selma. 2009. "Smuggling Intersectionality into the Study of Masculinity: Some Methodological Challenges [Conference paper]". Presented at Feminist Research Methods: An International Conference, University of Stockholm, 4-9 February, 2009.

Bowleg, Lisa. 2008. “When Black + Lesbian + Woman $\neq$ Black Lesbian Woman: The Methodological Challenges of Qualitative and Quantitative Intersectionality Research.” Sex Roles 59 (5-6): 312-325.

Brekhus, Wayne. 1998. "A sociology of the unmarked: Redirecting our focus." Sociological Theory 16(1): 34-51.

Bridges, Tristan. 2013. "Issues of Intimacy, Masculinity and Ethnography”. In Men, Masculinities and Methodologies, edited by Barbara Pini, and Bob Pease, 53-63. Basingstoke and New York: Palgrave Macmillan.

Bridges, Tristan, and C. J. Pascoe. 2014. "Hybrid Masculinities: New Directions in the Sociology of Men and Masculinities”. Sociology Compass 8 (3): 246-258.

Bridges, Tristan. 2019. "The Costs of Exclusionary Practices in Masculinities Studies." Men and Masculinities 22(1): 16-33.

Chase, Susan E. 1995. Ambiguous empowerment: The work narratives of women school superintendents. Amherst: University of Massachusetts Press.

Cho, Sumi, Kimberlé Williams Crenshaw, and Leslie McCall. 2013. "Toward a field of intersectionality studies: Theory, applications, and praxis." Signs: Journal of Women in Culture and Society 38(4): 785-810. 
Choo, Hae Yeon, and Myra Marx Ferree. 2010. "Practicing intersectionality in sociological research: A critical analysis of inclusions, interactions, and institutions in the study of inequalities." Sociological Theory 28(2): 129-149.

Collinson, David, and Jeff Hearn. 1994. "Naming Men as Men: Implications for Work, Organization and Management." Gender, Work and Organization 1(1): 2-22.

Crenshaw, Kimberlé. 1989. "Demarginalizing the Intersection of Race and Sex: A Black Feminist Critique of Antidiscrimination Doctrine, Feminist Theory and Antiracist Politics." University of Chicago Legal Forum 140: 139-167.

Crenshaw, Kimberlé. 1991. "Mapping the Margins: Intersectionality, Identity Politics, and Violence Against Women of Color." Stanford Law Review 43(6): 1241-1299.

Davis, Kathy. 2008. "Intersectionality as buzzword: A Sociology of Science Perspective on What Makes a Feminist Theory Successful." Feminist Theory 9(1): 67-85.

Donaldson, Mike, and Scott Poynting. 2013. "Peering Upwards: Researching Ruling-Class Men.” In Men, Masculinities and Methodologies, edited by Barbara Pini, and Bob Pease, 157-169. Basingstoke and New York: Palgrave Macmillan.

Fotopoulou, Aristea. 2012. “Intersectionality Queer Studies and Hybridity: Methodological Frameworks for Social Research.” Journal of International Women's Studies 13: 19-32.

Frankenberg, Ruth. 1993. White Women, Race Matters: The Social Construction of Whiteness. Minneapolis: University of Minnesota Press.

Frankenberg, Ruth. 1997. Displacing Whiteness: Essays in Social and Cultural Criticism. Durham: Duke University Press.

Gubrium, Jaber F., and James A. Holstein. 2008. “Narrative Ethnography.” In Handbook of Emergent Methods, edited by Sharlene Nagy Hesse-Biber and Patricia Leavy, 241-264. New York: Guilford Press.

Gubrium, Jaber F., and James A. Holstein. 2009. Analyzing Narrative Reality. Thousand Oaks, CA: Sage.

Hancock, Ange-Marie. 2007. “When Multiplication Doesn’t Equal Quick Addition: Examining Intersectionality as a Research Paradigm." Perspectives on Politics 5(1): 63-79.

Harding, Sandra, and Kathryn Norberg. 2005. "New Feminist Approaches to Social Science Methodologies: An Introduction.” Signs 30(4): 2009-2015.

Hearn, Jeff. 2013. "Methods and Methodologies in Critical Studies on Men and Masculinities". In Men, Masculinities and Methodologies, edited by Barbara Pini and Bob Pease, 26-38. Basingstoke and New York: Palgrave Macmillan.

Heritage, John. 2008. "Conversation Analysis as Social Theory." In The New Blackwell Companion to Social Theory, edited by Bryan S. Turner, 300-320. Oxford: Blackwell.

Heritage, John, and Steven Clayman. 2011. Talk in Action: Interactions, Identities, and Institutions. Vol. 44. Oxford: Blackwell.

Jimerson, Jason B., and Matthew K. Oware. 2006. "Telling the Code of the Street: An Ethnomethodological Ethnography." Journal of Contemporary Ethnography 35(1): 24-50.

Jovchelovitch, Sandra, and Bauer, Martin. 2000. "Narrative Interviewing." In Qualitative Researching with Text, Image and Sound: A Practical Handbook, edited by Martin Bauer, and George Gaskell, 57-74. London: Sage.

Kantola, Johanna. 2009. "Tackling Multiple Discrimination: Gender and Crosscutting Inequalities in Europe." In Teaching Intersectionality: Putting Gender at the Centre, edited by Franken, Martha, Alison E. Woodward, Anna Cabo Cardona, and Barbara Bagilhole, 15-30. ATHENA3 Advanced Thematic Network in Women's Studies in Europe. University of Utrecht and Centre for Gender Studies, Stockholm University. 
Kirsch, Gesa. 1999. Ethical Dilemmas in Feminist Research: The Politics of Location, Interpretation, and Publication. New York: State University of New York Press.

Lawler, Steph. 2002. "Narrative in Social Research." In: Qualitative Research in Action, edited by Tim May, 242-259. London: Sage.

Lewis, Gail. 2009. "Celebrating Intersectionality? Debates on a Multi-faceted Concept in Gender Studies: Themes from a Conference.” European Journal of Women's Studies 16(3): 203-210.

Liddicoat, Anthony. 2007. An Introduction to Conversation Analysis. London and New York: Continuum.

Ludvig, Alice. 2006. “Differences Between Women? Intersecting Voices in a Female Narrative. "European Journal of Women's Studies 13(3): 245-258.

Lutz, Helma. 2015. "Intersectionality as a Method." DiGeSt. Journal of Diversity and Gender Studies 2(1-2): 39-44.

Lykke, Nina. 2010. Feminist Studies: A Guide to Intersectional Theory, Methodology and Writing. New York: Routledge.

Matsuda, Mari. 1991. "Beside My Sister, Facing the Enemy: Legal Theory out of Coalition." Stanford Law Review 43(6): 1183-1192.

McCall, Leslie. 2005. "The Complexity of Intersectionality." Signs: Journal of Women in Culture and Society 30(3): 1771-1800.

Phoenix, Ann. 2008. "Analysing Narrative Contexts.” In Doing Narrative Research, edited by Molly Andrews, Corinne Squire, and Maria Tamboukou, 65-78. London: Sage.

Pease, Bob. 2010. Undoing Privilege: Unearned Advantage in a Divided World. London, New York: Zed Books.

Pease, Bob. 2014. "Reconstructing Masculinity or Ending Manhood? The Potential and Limitations of Transforming Masculine Subjectivities for Gender Equality." In Alternative Masculinities for a Changing World, edited by Àngels Carabí, and Josep Armengol, 17-34. New York, NY: Palgrave Macmillan.

Pini, Barbara, and Bob Pease. 2013. "Gendering Methodologies in the Study of Men and Masculinities." Men, Masculinities and Methodologies, edited by Barbara Pini, and Bob Pease, 1-25. Basingstoke and New York: Palgrave Macmillan.

Robinson, Sally. 2000. Marked Men. White Masculinity in Crisis. New York: Columbia University Press.

Shields, Stephanie A. 2008. "Gender: An Intersectionality Perspective." Sex Roles 59(5-6): 301-311.

Taylor, Yvette, Sally Hines, and Mark E. Casey. 2010. “Introduction.” In Theorizing Intersectionality and Sexuality, edited by Yvette Taylor, Sally Hines, and Mark E. Casey, 1-12. Basingstoke and New York: Palgrave Macmillan.

Twine, France W. 1997. "Brown-skinned White Girls: Class, Culture, and the Construction of White Identity in Suburban Communities." In Displacing Whiteness Essays in Social and Cultural Criticism, edited by Ruth Frankenberg, 214-244. Durham: Duke University Press.

Twine, France W., and Jonathan Warren. 2000. Racing Research, Researching Race: Methodological Dilemmas in Critical Race Studies. New York: New York University Press.

Windsong, Elena A. 2016. "Incorporating intersectionality into research design: an example using qualitative interviews." International Journal of Social Research Methodology 21(2): 135-147.

Yuval-Davis, Nira. 2006. "Intersectionality and Feminist Politics." European Journal of Women's Studies 13(3): 193-209. 
